\title{
Research Communication Nitric Oxide Levels in Patients with Psoriasis Treated with Methotrexate
}

\author{
Nilgun Solak Tekin, ${ }^{1}$ Nilsel Ilter, ${ }^{2}$ Banu Sancak, ${ }^{3}$ Muge Guler Ozden, ${ }^{4}$ and Mehmet Ali Gurer ${ }^{2}$ \\ ${ }^{1}$ Department of Dermatology, Medical Faculty, Zonguldak Karaelmas University, 67600 Zonguldak, Turkey \\ ${ }^{2}$ Department of Dermatology, Medical Faculty, Gazi University, 06100 Ankara, Turkey \\ ${ }^{3}$ Department of Biochemistry, Medical Faculty, Gazi University, 06100 Ankara, Turkey \\ ${ }^{4}$ Department of Dermatology, Medical Faculty, Yeditepe University, 34100 Istanbul, Turkey
}

Received 13 February 2006; Revised 14 March 2006; Accepted 16 March 2006

Psoriasis is a chronic, recurrent, inflammatory, and hyperproliferative disease. Recently there have been studies regarding increases in the levels of NO in inflammatory dermatoses including psoriasis. In this study, 22 patients with psoriasis were scored with PASI (psoriasis area and severity index) and the levels of serum nitrite-nitrate were evaluated before and after therapy with methotrexate (Mtx). The results were compared with age- and sex-matched healthy volunteers. The relation of the results with the clinical severity and the cumulative Mtx dose were also evaluated. The serum levels of nitrite-nitrate of the psoriatic patients with active lesions were found to be significantly higher than the levels of the healthy volunteers and the patients after therapy. The elevated nitrite-nitrate serum levels in the inflammatory period may suggest the possible role of this mediator in the etiopathogenesis of psoriasis and the potential future use of NO inhibitors in the treatment of psoriasis.

Copyright (c) 2006 Nilgun Solak Tekin et al. This is an open access article distributed under the Creative Commons Attribution License, which permits unrestricted use, distribution, and reproduction in any medium, provided the original work is properly cited.

\section{INTRODUCTION}

Psoriasis is a common chronic skin disease mediated by cellular immune mechanisms and characterized by an intense neutrophile cell infiltrate and proliferative activation of epidermal keratinocytes. It is generally assumed that unbalanced immune responses contribute to the pathogenesis $[1,2]$. The exact sequence of events, as well as the molecular mediators that lead to hyperproliferative responses, is yet to be defined. As a potent regulator of keratinocyte growth and differentiation, the multifunctional signaling molecule nitric oxide $(\mathrm{NO})$ has been considered to be a strong candidate in the pathogenesis of psoriasis [3-5]. This heat-labile and unstable compound is synthesized in endothelial cells as well as neurons by constitutive NOS synthase (cNOS), while inducible NO synthase (iNOS) is found in leucocytes, macrophages, and mesengial cells. A small amount of NO produced by cNOS in endothelium is responsible for the relaxation of adjacent smooth muscles and prevents adhesion of platelets and leucocytes to the endothelium. This is the anti-inflammatory effect of NO [6]. However, when produced in large amounts NO can destroy tissues and impair immune response. High levels are demonstrated in immunological disorders like systemic lupus erythematosus or rheumatoid arthritis. Hence, inhibition of iNOS is an effective modality of treatment in these conditions [7]. The production of nitric oxide is $\sim 10$-fold higher in nonlesional skin of psoriatics and $\sim 10$-fold higher again in the plaques themselves [8].

Although studies showed the elevated NO levels in psoriatic tissue samples, as far as we know there are very few studies exploring serum NO levels in psoriatic patients [9-14].

Methotrexate (Mtx) is an analogue of folic acid and an antiproliferative agent through its competitive binding to dihydrofolate reductase. Although the effectiveness of Mtx in the treatment of psoriasis is very well established, the mechanism of action is poorly understood $[15,16]$. There are some studies suggesting that Mtx decreases the NO levels in psoriasis [13].

In our study, the role of $\mathrm{NO}$ in the pathogenesis of psoriatic inflammation, the relation between NO and PASI and the effect of methotrexate on $\mathrm{NO}$ in psoriatic patients serum were investigated.

\section{PATIENTS AND METHODS}

Twenty-two patients (sixteen males and six females) with clinically active psoriasis vulgaris and twenty-one healthy 
controls (fourteen males and seven females) were selected from the outpatient clinic of Department of Dermatology, Gazi University Hospital. Active psoriasis was defined as plaques increasing in size and number at the time of research. The ages of patients and controls ranged from 18 to 59 years (mean $35.00 \pm 11.80$ ) and 17 to 46 years (mean 29.48 \pm 7.54 ), respectively. The groups were similar in most demographic characteristics. The duration of psoriasis (years) ranged from 1 to 20 (mean $8.80 \pm 6.52$ ). Informed consent was obtained after the study had been fully explained. All patients had clinical and histopathological diagnosis for chronic plaque-type psoriasis.

The assessment of the severity and extent of disease was done by PASI score. The inclusion criterion was an active disease which had PASI score above [16]. The exclusion criteria were coexisting inflammatory skin disease, topical therapy within 4 weeks, systemic therapy or photochemotherapy within 3 months. Pregnant or lactating women and patients with systemic disease were also excluded.

Five $\mathrm{ml}$ of venous blood was collected using vacutainer tubes with ethylenediaminetetraacetic acid (EDTA) as anticoagulant and centrifuged at $1000 \mathrm{~g}$ within $30 \mathrm{~min}$ of collection. Serum samples of patient and control groups were stored at $-70^{\circ} \mathrm{C}$ until they were assayed in one run.

The dose of methotrexate was $20 \mathrm{mg}$ per week (given in three divided doses with a 12-hour interval between doses). Clinical response was usually evident in 7-14 days, but maximal response was taken between 4 th-8th weeks. As soon as acceptable control was achieved, the dosage was lowered or the interval between doses was extended. Patients who were treated with methotrexate underwent the following laboratory tests every two weeks during the first month and monthly thereafter, a complete blood count and assays of electrolytes, serum creatinine, blood urea nitrogen, aspartate aminotransferase, alanine aminotransferase, alkaline phosphatase, and bilirubine.

Serum samples were obtained before Mtx therapy, and at the time the lesions completely disappeared (PASI $=0$ ). The cumulative Mtx dose was calculated when PASI $=0$. The length of the therapy and the cumulative Mtx dose were different for each psoriasis patient.

The results were compared with 21 healthy volunteers. The relation of the results with the clinical severity and the cumulative Mtx dose was also evaluated. As NO is an unstable molecule, it is rapidly converted to nitrates and nitrites in the body; hence their concentration is parallel to NO levels.

\section{Nitrite determination}

Nitrite was measured by using a Griess reaction [17]. The results were given as $\mu \mathrm{mol} / \mathrm{L}$.

\section{Nitrate determination}

Nitrate was measured using the enzymatic one-step assay with nitrate reductase [18]. This method is based on the reduction of nitrate to nitrite by nitrate reductase in the presence of $\beta$-NADPH. Tubes containing $250 \mu \mathrm{l}$ of $100 \mathrm{mmol} / \mathrm{l}$ potassium phosphate buffer ( $\mathrm{pH} 7.5$ ), $50 \mu \mathrm{l}$ of $12 \mathrm{mmol} / \mathrm{l} \beta$ $\mathrm{NADPH}$, and $100 \mu \mathrm{l}$ sample were equilibrated at $25^{\circ} \mathrm{C}$. To start the enzymatic reaction, $40 \mu \mathrm{l}$ of $500 \mathrm{U} / \mathrm{l}$ nitrate reductase was added. The samples were incubated for $45 \mathrm{~min}$ in the dark. The oxidation of $\beta$-NADPH was monitored in terms of the decrease in absorbency at $340 \mathrm{~nm}$. The method of standard addition was used to minimize the effect of interfering substances from the serum. The results are given as micromoles per liter. Samples with internal standard, and serum and reagent blanks were also analyzed.

\section{Statistical analysis}

To compare differences in nitrite-nitrate levels, results (before and after therapy, and nonpsoriatic patients) were assessed using Wilcoxons test and Mann-Whitney U test. Correlations between PASI score, cumulative MTX dose, and nitrite-nitrate serum levels were analyzed with the Spearman rho correlation. SPSS Windows release 11.5 (SPSS Inc., USA) was used. All values were expressed as mean \pm standard of means (SEM) unless stated otherwise. Statistical significance level was set to 0.05 for all calculations.

\section{RESULTS}

All patients were successfully treated with Mtx according to the schedule. The mean PASI score was $36.10 \pm 1.87$ at the baseline of therapy and the mean cumulative Mtx dose was $235 \pm 22.34 \mathrm{mg}$ at the time the lesions completely disappear (PASI $=0)$. The patients tolerated the therapy well. And there were no significant adverse effects. The mean baseline values of nitrite-nitrate concentrations in the sera of psoriasis patients were $27.98 \pm 7.40 \mu \mathrm{mol} / \mathrm{L}$ and $85.28 \pm 10.45 \mu \mathrm{mol} / \mathrm{L}$, while that in the sera of patients after treatment were $10.028 \pm$ $2.05 \mu \mathrm{mol} / \mathrm{L}$ and $39.60 \pm 7.88 \mu \mathrm{mol} / \mathrm{L}$. The mean values of serum nitrite-nitrate concentrations of healthy controls were $2.98 \pm 0.77 \mu \mathrm{mol} / \mathrm{L}$ and $19.08 \pm 5.0 \mu \mathrm{mol} / \mathrm{L}$.

Serum levels of nitrite-nitrate were both significantly higher in patients with psoriasis before treatment than in controls and patients after treatment $(P<.05)$ (Figures 1 and 2). No correlation was found between PASI score and serum nitrite-nitrate levels before therapy in the patients $(r=-0.085$ and $p=0.708$ for nitrite; $r=0.368$ and $p=$ 0.092 for nitrate).

We found no correlation between cumulative Mtx dosage serum nitrite-nitrate levels in patients after treatment. $(r=$ -0.262 and $p=0.239$ for nitrite; $r=-0.094$ and $p=0.677$ for nitrate).

\section{DISCUSSION}

In recent years, the clonality of lymphocytes in psoriatic lesions and the increased cytokine release in that region are well established. Cytokines, such as IFN $\gamma, \mathrm{TNF} \alpha$, IL-8, IL-1, and IL-6, are most important ones $[9,19,20]$. An important marker of inflammation $\mathrm{NO}$ is one of these mediators. NO is a labile mediator that can be detected in high levels in the existence of these cytokines. NO is released continuously in low 


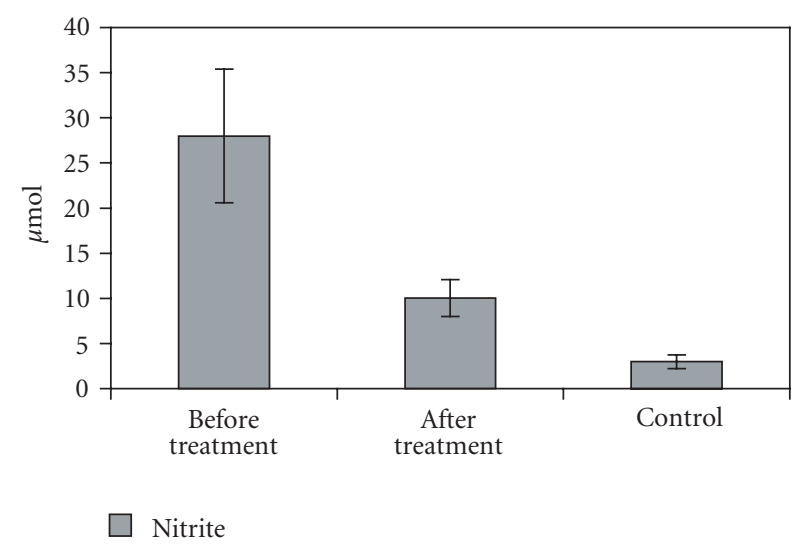

FIGURE 1: Serum levels of nitrite were significantly higher in patients with psoriasis before treatment than in controls and patients after treatment $(P<.05)$.

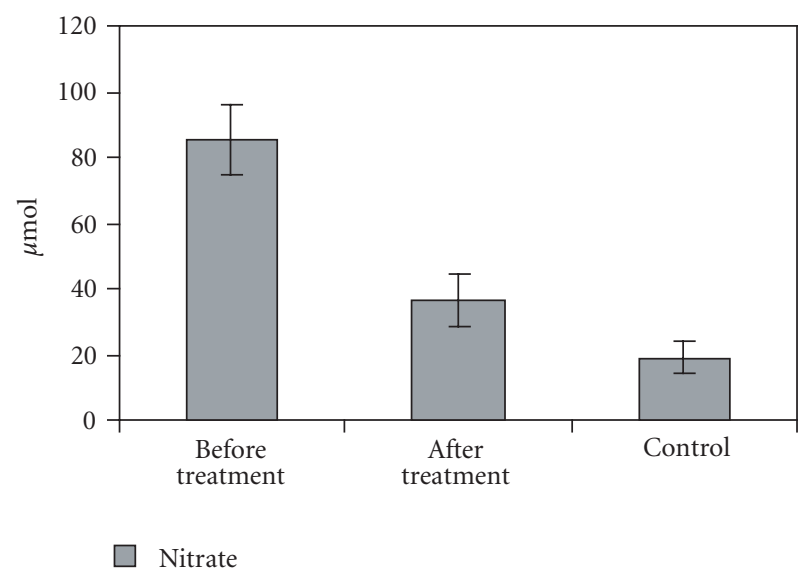

FIgURE 2: Serum levels of nitrate were significantly higher in patients with psoriasis before treatment than in controls and patients after treatment $(P<.05)$.

concentration while for high concentrations a stimulation is needed $[21,22]$. It has been shown that NO is increased in a number of skin disorders with a stimulation. In the lesional tissue samples of contact dermatitis, atopic dermatitis, systemic lupus erythematosus, and psoriasis, NO is significantly higher than controls [23-26]. Increased NO synthesis suggests a role for the pathogenesis of psoriasis. NO may trigger the psoriatic disease process at least partly through increment of the release and actions of calcitonin gene-related peptide and substance $P$, which are considered to play important roles in the pathomechanism of psoriasis by inducing the production of adhesion molecules, keratinocyte hyperproliferation, mast cell degranulation, vasodilatation, and chemotaxis of neutrophils [27]. Cals-Gierson and Ormerod have suggested that NO stimulates epithelial cells to release chemokines and growth mediators which appear to be important for keratinocyte proliferation and angiogenesis [28].
In previous studies, NO levels have been measured in tissue samples from psoriasis patients $[8,9,11,13,14]$. However, we could find very few similar research investigating nitrite and nitrate levels in blood samples of psoriatic patients $[10,12]$. And there has been no study showing the effects of the Mtx upon NO levels in human sera. NO is a highly reactive free radical with a very short half life. The labile nature of NO makes it impossible to analyze serum and tissue levels. The nonfunctional metabolites of NO; nitrite and nitrate are helpful to search the amount of NO. Nitrite levels are considered the marker of NO in tissue and other body fluids. It is important to study nitrate levels as the nitrite is reduced into nitrate by oxyhemoglobine, in blood [11-13, 17].

Orem et al studied NO levels in 17 patients of psoriasis during active and inactive phases [12]. In that study the baseline serum nitrite-nitrate levels of severe psoriatic patients (the mean PASI score was 16.5) compared with after topical treatment results and found only the nitrite levels are significantly different. They observed no significant difference for nitrate. They also demonstrated a positive correlation between nitrite levels and PASI scores. There was no healthy control group in that study.

Gokhale et al found significantly high NO levels in patients with active disease as compared to normal individuals [10]. In that study there was significant positive correlation between the severity and duration of disease and NO levels in patients with chronic plaque-type psoriasis.

In our study all the patients had the PASI score above 15 before treatment. The baseline serum nitrite-nitrate levels were significantly higher than the levels in nonlesional $($ PASI $=0)$ period. Serum nitrite and nitrate levels of the control group were significantly lower than those of the psoriatic patients during the inflammatory stage. These findings suggest a possible role of NO in the pathogenesis of psoriasis during the inflammatory phase. The results of our study are consistent with the findings of previous studies in which $\mathrm{NO}$ and iNOS levels in the tissue samples were investigated $[11,14,18,25,29]$.

The nitrite plasma levels in the control group were significantly lower than in the psoriasis patients both before and after treatment in our study $(p=0.0004)$. The nitrate levels after treatment were higher than the control group but the difference was not statistically significant $(P>.05)$. We suggest that serum nitrate level may be an important indicator for the lesional period. The finding of higher serum nitritenitrate levels than the healthy controls supports the idea that the inflammation in psoriasis does not descend the normal levels in clinically healed psoriatic patients. This opinion is supported by the results of studies in the literature showing the microscopic inflammation in nonlesional tissue samples $[1,8,13,14]$.

As far as we know there are only two studies exploring the correlation between psoriasis severity and NO levels in the literature. Orem et al showed a positive relation between serum nitrite and PASI [12]. Gokhale et al found significant positive correlation between the severity of disease and $\mathrm{NO}$ levels in patients with chronic plaque-type psoriasis [10]. But we found no correlation between serum nitrite-nitrate 
levels and PASI in our study. Our results support the theory that the serum nitrite-nitrate levels indicate the systemic inflammation and establish a relation between $\mathrm{NO}$ and psoriasis activity that is possible in laboratory conditions. However, it seems that the nitrite-nitrate concentration is not a biomarker of psoriasis severity according to our findings.

Methotrexate was thought to act primarily on the rapidly dividing basal keratinocytes of the psoriatic lesion. The group of Weinstein demonstrated that proliferating lymphoid cells in psoriatic lesions are over 1000 times more sensitive to the cytotoxic effects of Mtx than primary human keratinocytes [30]. It also has been shown that Mtx exerts anti-inflammatory effects mediated through intracellular accumulation of 5-aminoimidazole-4-carboxyamide ribonucleotide, thereby increasing the release of adenosine. Adenosine exerts anti-inflammatory effects mainly on neutrophils, where an inhibition of adhesion and reactive oxygen intermediate production has been demonstrated [31].

The basic studies exploring the effect of Mtx on NO levels are in vitro. These studies emphasize that Mtx inhibits NO by means of constitutive and/or inducible NO synthases inhibition [32-35]. There are some studies suggesting that Mtx decreases the NO levels in psoriasis [13] Although there is no relation between the cumulative dosage and nitrite-nitrate levels in noninflammatory period in our study, nitrite-nitrate levels after treatment were significantly lower than the levels before. This result may show that Mtx decreases NO levels and makes an anti-inflammatory effect independent of the cumulative dosage. This finding is similar to other reports in the literature $[13,35,36]$. We can suggest that immunological and inflammatory mechanisms are important in the etiopathogenesis of psoriasis and that NO plays a role in both mechanisms. The results in our study are comparable with the studies investigating the lesional psoriatic tissue iNOS and NO levels $[9,11,14]$. This relationship between psoriasis and NO may pave the way for novel therapeutic approaches such as selective iNOS inhibitors in the management of this difficult disease.

\section{REFERENCES}

[1] Bruch-Gerharz D, Ruzicka T, Kolb-Bachofen V. Nitric oxide in human skin: current status and future prospects. The Journal of Investigative Dermatology. 1998;110(1):1-7.

[2] Schlaak JF, Buslau M, Jochum W, et al. T cells involved in psoriasis vulgaris belong to the Th1 subset. The Journal of Investigative Dermatology. 1994;102(2):145-149.

[3] Bos JD. Skin Immune System. 2nd ed. Boca Raton, Fla: CRC Press; 1997.

[4] Bos JD, De Rie MA. The pathogenesis of psoriasis: immunological facts and speculations. Immunology Today. 1999;20(1): 40-46.

[5] Ortonne N, Ortonne JP. Psoriasis. Patogénie. La Presse Médicale. 1999;28(23):1259-1265.

[6] Davies MG, Fulton GJ, Hagen PO. Clinical biology of nitric oxide. The British Journal of Surgery. 1995;82(12):1598-1610.

[7] Clancy RM, Amin AR, Abramson SB. The role of nitric oxide in inflammation and immunity. Arthritis and Rheumatism. 1998;41(7):1141-1151.
[8] Weller R, Ormerod A. Increased expression of inducible nitric oxide (NO) synthase. The British Journal of Dermatology. 1997;136(1):136-137.

[9] Bruch-Gerharz D, Fehsel K, Suschek C, Michel G, Ruzicka T, Kolb-Bachofen V. A proinflammatory activity of interleukin 8 in human skin: expression of the inducible nitric oxide synthase in psoriatic lesions and cultured keratinocytes. The Journal of Experimental Medicine. 1996;184(5):2007-2012.

[10] Gokhale NR, Belgaumkar VA, Pandit DP, Deshpande S, Damle DK. A study of serum nitric oxide levels in psoriasis. Indian Journal of Dermatology, Venereology and Leprology. 2005;71(3):175-178.

[11] Kolb-Bachofen V, Fehsel K, Michel G, Ruzicka T. Epidermal keratinocyte expression of inducible nitric oxide synthase in skin lesions of psoriasis vulgaris. Lancet. 1994;344(8915):139.

[12] Orem A, Aliyazicioglu R, Kiran E, Vanizor B, Cimnocodeit G, Deger O. The relationship between nitric oxide production and activity of the disease in patients with psoriasis. Archives of Dermatology. 1997;133(12):1606-1607.

[13] Ormerod AD, Weller R, Copeland P, et al. Detection of nitric oxide and nitric oxide synthases in psoriasis. Archives of Dermatological Research. 1998;290(1-2):3-8.

[14] Sirsjo A, Karlsson M, Gidlof A, Rollman O, Torma H. Increased expression of inducible nitric oxide synthase in psoriatic skin and cytokine-stimulated cultured keratinocytes. The British Journal of Dermatology. 1996;134(4):643-648.

[15] Heenen M, Laporte M, Noel JC, de Graef C. Methotrexate induces apoptotic cell death in human keratinocytes. Archives of Dermatological Research. 1998;290(5):240-245.

[16] Heydendael VM, Spuls PI, Opmeer BC, et al. Methotrexate versus cyclosporine in moderate-to-severe chronic plaque psoriasis. The New England Journal of Medicine. 2003;349(7): 658-665.

[17] Green LC, Wagner DA, Glogowski J, Skipper PL, Wishnok JS, Tannenbaum SR. Analysis of nitrate, nitrite, and [15N]nitrate in biological fluids. Analytical Biochemistry. 1982;126(1):131138.

[18] Bories PN, Bories C. Nitrate determination in biological fluids by an enzymatic one-step assay with nitrate reductase. Clinical Chemistry. 1995;41(6 pt 1):904-907.

[19] Krischel V, Bruch-Gerharz D, Suschek C, Kroncke KD, Ruzicka T, Kolb-Bachofen V. Biphasic effect of exogenous nitric oxide on proliferation and differentiation in skin derived keratinocytes but not fibroblasts. The Journal of Investigative Dermatology. 1998;111(2):286-291.

[20] Corradin SB, Fasel N, Buchmuller-Rouiller Y, Ransijn A, Smith J, Mauel J. Induction of macrophage nitric oxide production by IFN $\gamma$ and TNF $\alpha$ is enhanced by IL-10. European Journal of Immunology. 1993;23(8):2045-2048.

[21] Anggard E. Nitric oxide: mediator, murderer, and medicine. Lancet. 1994;343(8907):1199-1206.

[22] Lowenstein CJ, Dinerman JL, Snyder SH. Nitric oxide: a physiologic messenger. Annals of Internal Medicine. 1994;120(3): 227-237.

[23] Gilkeson G, Cannon C, Oates J, Reilly C, Goldman D, Petri $\mathrm{M}$. Correlation of serum measures of nitric oxide production with lupus disease activity. Journal of Rheumatology. 1999;26 (2):318-324.

[24] Rowe A, Farrel AM, Bunker CB. Constitutive endothelial and inducible nitric oxide synthase in inflammatory dermatoses. The British Journal of Dermatology. 1997;136(1):18-23.

[25] Sahin S, Önder M, Sancak B, Bukan N, Gürer MA. The role of nitric oxide in allergic contact dermatitis. Archives of Dermatological Research. 2001;293(4):214-217. 
[26] Taniuchi S, Kojima T, Hara Mt K, et al. Increased serum nitrate levels in infants with atopic dermatitis. Allergy. 2001;56 (7):693-695.

[27] Namazi MR. A complementary note on the Morhenn's hypothesis on the pathomechanism of psoriasis. Immunology Letters. 2003;85(3):223.

[28] Cals-Grierson MM, Ormerod AD. Nitric oxide function in the skin. Nitric Oxide. 2004;10(4):179-193.

[29] Kuo PC, Schroeder RA. The emerging multifaceted roles of nitric oxide. Annals of Surgery. 1995;221(3):220-235.

[30] Weinstein GD, Jeffes E, McCullough JL. Cytotoxic and immunologic effects of methotrexate in psoriasis. Journal of Investigative Dermatology. 1990;95(5):49S-52S.

[31] Genestier L, Paillot R, Quemeneur L, Izeradjene K, Revillard JP. Mechanisms of action of methotrexate. Immunopharmacology. 2000;47(2-3):247-257.

[32] Corradin SB, Fasel N, Buchmüller-Roniller Y, Ransisjn A, Smith J, Manuel J. Induction of macrophage nitric oxide production by IFN $\gamma$ and TNF $\alpha$ is enhanced by IL-10. European Journal of Immunology. 1993;23(8):2045-2048.

[33] Olsen EA. The pharmacology of methotrexate. Journal of the American Academy of Dermatology. 1991;25(2 pt 1):306-318.

[34] Omata T, Segawa Y, Inoue N, Tsuzuike N, Itokazu Y, Tamaki $\mathrm{H}$. Methotrexate suppresses nitric oxide production ex vivo in macrophages from rats with adjuvant-induced arthritis. Research in Experimental Medicine. 1997;197(2):81-90.

[35] Robbins RA, Jinkins PA, Bryan TW, Prado SC, Milligan SA. Methotrexate inhibition of inducible nitric oxide synthase in murine lung epithelial cells in vitro. American Journal of Respiratory Cell and Molecular Biology. 1998;18(6):853-859.

[36] Durez P, Appelboom T, Vray B, Pira C, Goldman M. Methotrexate inhibits LPS-induced tumor necrosis factor production in vivo. European Cytokine Network. 1998;9(4):669-672. 


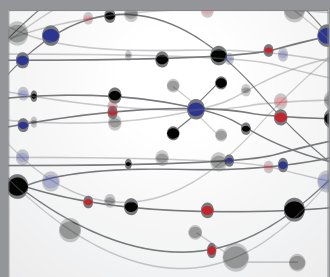

The Scientific World Journal
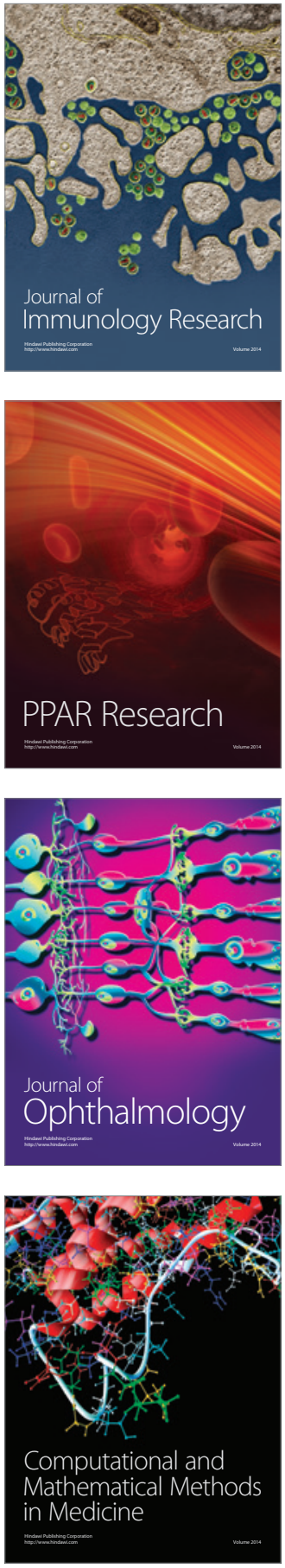

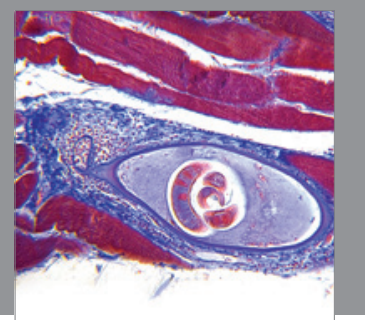

Gastroenterology

Research and Practice
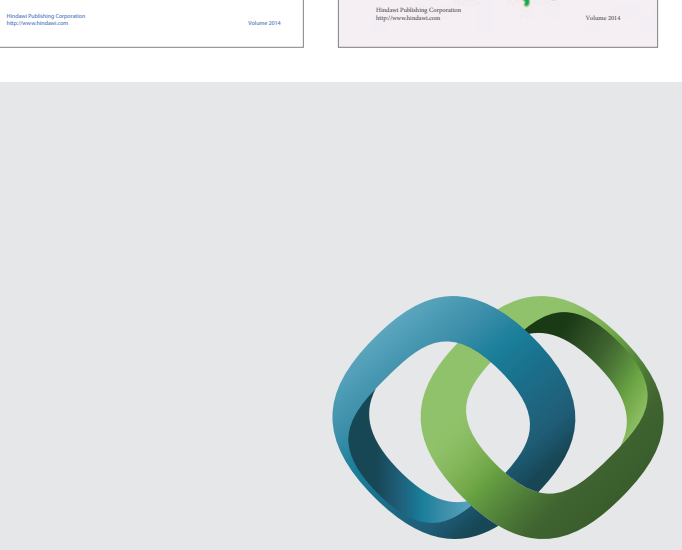

\section{Hindawi}

Submit your manuscripts at

http://www.hindawi.com
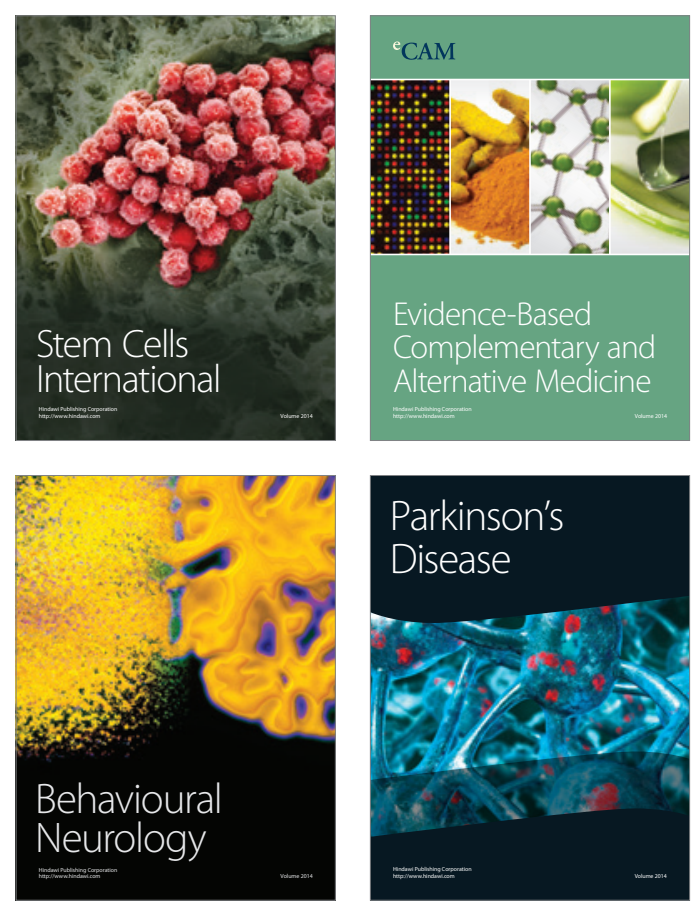

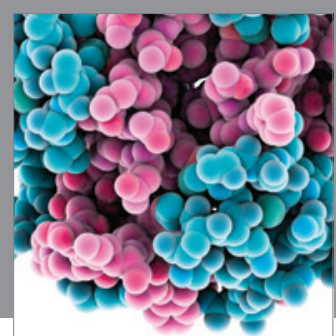

Journal of
Diabetes Research

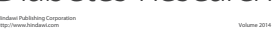

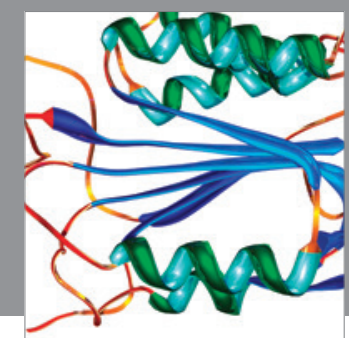

Disease Markers
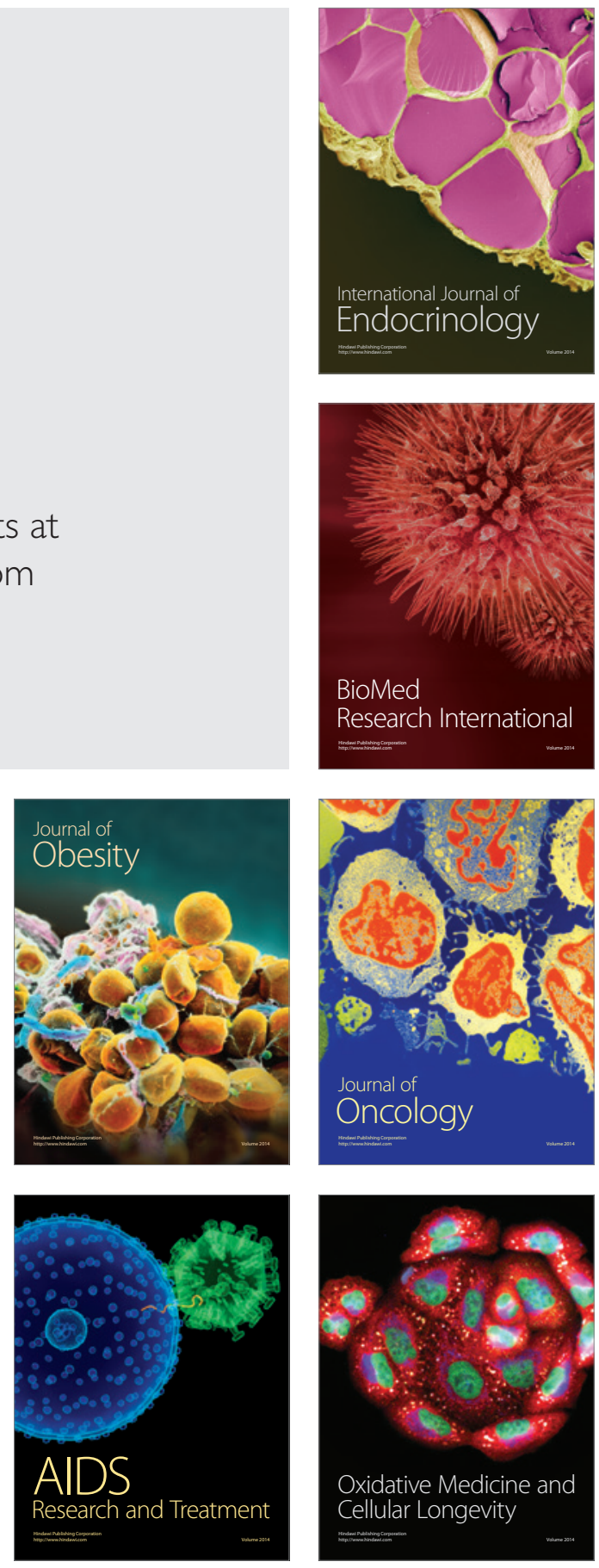